\title{
METODE-METODE PENELITIAN MISIOLOGIS FRANS WIJSEN
}

\begin{tabular}{|c|c|c|c|}
\hline \multicolumn{4}{|c|}{ KEES DE JONG* } \\
\hline \multirow{6}{*}{$\begin{array}{r}\text { Religious Discourse, } \\
\text { Social Cohesion and Conflict } \\
\text { Studying Muslim-Christian Relations }\end{array}$} & Judul Buku & : & $\begin{array}{l}\text { RELIGIOUS DISCOURSE, SOCIAL } \\
\text { COHESION AND CONFLICT: Studying } \\
\text { Muslim-Christian Relation (Religions and } \\
\text { Discourse Series Vol. 55) }\end{array}$ \\
\hline & Pengarang & : & Frans Wijsen \\
\hline & ISBN & : & $978-3-0353-0484-8$ \\
\hline & Terbit & : & 2013 \\
\hline & Tebal & : & $x i+219$ halaman \\
\hline & Penerbit & : & Peter Lang, Bern \\
\hline \multicolumn{4}{|l|}{ ntroductions Introductions Int! } \\
\hline \multirow[t]{6}{*}{$\begin{array}{l}\text { Frans Wisen } \\
\text { Christianity and Other Cultures } \\
\text { Introduction to Mission Studies }\end{array}$} & Judul Buku & : & $\begin{array}{l}\text { CHRISTIANITY AND OTHER CULTURES. } \\
\text { Introduction to Mission Studies }\end{array}$ \\
\hline & Pengarang & & Frans Wijsen \\
\hline & ISBN & & $978-3-643-90579-6$ \\
\hline & Terbit & & 2015 \\
\hline & Tebal & & 267 halaman \\
\hline & Penerbit & & LIT Verlag, Zürich \\
\hline roductions Introductions Int! & & & \\
\hline
\end{tabular}

* Dosen Fakultas Teologi Universitas Kristen Duta Wacana, Yogyakarta. Email: kdejong51@gmail.com

(C) KEES DE JONG | DOI: 10.21460/gema.2016.12.243

This work is licenced under a Creative Commons Attribution-NonCommercial 4.0 International Licence. 


\section{PENDAHULUAN}

Biasanya riwayat hidup seorang teolog praktis/misiolog sangat memengaruhi perkembangan pikiran teologis/misiologis-nya. Hal itu juga berlaku untuk Frans Wijsen. Dia adalah anggota asosiasi Societas Misi Afrika (SMA) mengikuti studi teologinya pada Sekolah Tinggi Teologi dan Pastorat (HTP), yang di kemudian hari menjadi Universitas Teologi dan Pastorat (UTP) di Heerlen dengan bidang utama misiologi. Keunikan HTP/UTP pada waktu itu adalah bahwa teologi pastoral diajarkan secara interdisipliner bersama dengan bidang-bidang lain, yaitu: sosiologi, antropologi, psikologi, bahkan ilmu statistik sudah diajarkan. UTP akhirnya bergabung dengan Fakultas Teologi dari Universitas Radboud di Nijmegen. Dari tahun 19841988, sesudah menyelesaikan studi di UTP dengan gelar drs., Wijsen bekerja dan membuat penelitian di Tanzania, dan, sejak 1985, sekaligus mengajar paruh waktu di UTP. Pada permulaan tahun 1990-an dia menulis disertasinya (Wijsen, 1993) tentang agama resmi dan agama populer dalam konteks Tanzania, menganalisisnya berdasarkan teori lingkaran pastoral. ${ }^{1}$ Kemudian ia menjadi dosen tetap di bidang misiologi dan pada tahun 2000 dan menjadi profesor di bidang studi-studi misi di Radboud Universiteit, Nijmegen. ${ }^{2}$ Dalam tahun 1994 ia menjadi koordinator suatu proyek dari beberapa fakultas teologi Belanda untuk mempersiapkan program pendidikan pastoral praktis tingkat pascasarjana bagi fakultas teologi UKDW, dengan inti pengajaran pembangunan jemaat, teologi praktis, dan teologi empiris. Sejak waktu itu hingga kini teologi praktis empiris adalah bidang khas dari Radboud Universitas Nijmegen. Pada tahun 2005, bersama dengan beberapa ahli lain yang menggunakan metode lingkaran pastoral, antara lain: Peter Henriot, SJ., ia menyelenggarakan suatu seminar ilmiah tentang revisi lingkaran pastoral (Wijsen dkk., 2005). E.G. Singgih dan J.B. Banawiratma juga memberi kontribusi dari konteks Indonesia dalam seminar ini. Kemudian Wijsen tertarik, karena konteks Indonesia dan Tanzania mirip, untuk memperdalam hubungan antar agama, terutama agama Islam dan Kristiani dan sekaligus memperdalam hubungan dengan kebudayaan asli, dari segi teologi interkultural. Ia juga meneliti lebih dalam pergeseran pusat kekristenan dari dunia "Barat" ke dunia "Selatan", dan berdasarkan itu ia terlibat aktif dalam organisasi di suatu kongres untuk merayakan 75 tahun pendidikan misiologi di Nijmegen, di mana buku Philip Jenkins (2007) tentang pergeseran dari pusat kekristenan dari dunia Barat ke dunai Selatan, dibahas secara kritis. Kongres dibuka oleh Philip Jenkins sendiri sebagai key-note speaker dan hasil makalah-makalah dipublikasikan oleh Frans Wijsen bersama Robert Schreiter (Wijsen dan Schreiter, 2007). ${ }^{3}$ Tahun-tahun terakhir ini, dia merasa, bahwa lingkaran pastoral yang terutama meneliti struktur-struktur konteks 
masyarakat tidak seluruhnya memadai lagi, dan juga sistem perbandingan agama-agama dan kebudayaan-kebudayaan sekarang sudah tidak terlalu memuaskan lagi (lih. Wijsen, 2012: 7391). Menurutnya mengganti misiologi dengan teologi interkultural, seperti yang dilakukan di Eropa dan terutama di Jerman sejak tahun 1990-an, tidaklah tepat. Teologi interkultural adalah suatu metode yang bermanfaat untuk misiologi, tetapi tidak menggantikan misiologi. Jika memperhatikan perkembangan misi di seluruh dunia saat ini, misiologi sendiri masih sangat dibutuhkan. Menurutnya suatu metode yang menarik untuk membuat penelitian lapangan sekarang ini adalah Critical Discourse Analysis (CDA, 'analisa wacana Kritis'), dan salah satu hasil dari penelitian dengan metode tersebut adalah bukunya yang berjudul Religious Discourse, Social Cohesion and Conflict: Studying Muslim-Christian Relations yang menarik untuk konteks Indonesia, karena dengan metode CDA dia meneliti hubungan antara Muslim dan Kristen di Tanzania maupun di Indonesia. Berdasarkan penelitian sebagai seorang misiolog lintas ilmu selama kira-kira 30 tahun dan sekarang 16 tahun sebagai profesor dia juga memberi sumbangan sangat berharga dengan buku Christianity and Other Cultures, suatu kumpulan artikel-artikel yang pernah dia tulis dengan subjudul: Introduction to Mission Studies karena dia sadar bahwa dia sebenarnya juga harus "mengisi 'kekosongan' selama 15 tahun sebagai profesor ialah membahas topik 'how to do' Mission studies”' (Foreword, p. 7).

Seperti sudah disebut di atas, salah satu metode menarik untuk membuat penelitian adalah CDA, yakni langsung menerima informasi dari orang melalui wawancara atau Focus Group Discussion (FGD, 'diskusi kelompok yang berfokus'), ditambah dengan informasi dari media seperti radio, t.v., video, $\mathrm{CD}$, internet, untuk mengetahui bagaimana mereka mengalami dan sekaligus dipengaruhi oleh konteks mereka. Pengalaman ini menjadi ‘teks, wacana', tentang misalnya bagaimana mereka mengalami hubungan antar agama dan kemudian wacana-wacana tersebut dianalisa. Selain itu, Wijsen juga yakin, bahwa keterbukaan untuk orang lain, karena mereka adalah yang liyan, mempunyai kecenderungan untuk melupakan, bahwa kita sebagai manusia sebenarnya juga mempunyai banyak kebersamaan, misalnya saja dari segi fisik, juga dari fungsi otak (Wijsen, 2014: 185-192). ${ }^{4}$

\section{BUKU RELIGIOUS DISCOURSE}

Garis besar tulisan Wijsen adalah sebagai berikut: sesudah kata pengantar dengan judul "Dari Perbandingan ke Konversasi/Percakapan", Wijsen melanjutkan dengan bab 1 tentang 
perkembangan hubungan-hubungan interreligius sesudah perang dingin antara dunia Barat (kapitalis, Amerika Serikat dan Eropa Barat) dengan dunia Timur (komunis, Eropa Timur dan Rusia) diakhiri dengan "runtuhnya tembok pemisahan antara dua dunia itu di Berlin" (1989). Bab 2-4, dibahas perkembangan teori-teori bagi studi interreligius. Kemudian dideskripsikanlah hasil penelitian berdasarkan CDA tentang hubungan Islam-Kristen di Tanzania (bab 5) dan di Indonesia (bab 6). Diikuti oleh 3 bab analisa dari data-data tersebut. Bab 10 merupakan kesimpulan buku, ialah suatu rumusan teori "percakapan" bagi hubungan antaragama. Buku ini diakhiri dengan epilog tentang agama dalam ruang publik, dengan suatu rumusan tentang hubungan Islam-Kristen, transformasi identitas religius beserta teori dan metode bagi studi-studi interreligius. Hal yang menarik dari buku ini adalah bahwa teori, metode, dan hasil penelitian dideskripsikan dengan baik dan dengan itu ditawarkan suatu metode baru untuk meneliti hubungan antar agama-agama secara praktis dan sekaligus merumuskan teologi interreligius secara baru berdasarkan hasil penelitian itu. Tulisan Wijsen tajam, singkat, dan jelas, tidak ada uraian-uraian panjang lebar, tetapi untuk mengerti isi diberi cukup banyak contoh. Maka tidak mungkin memberi garis besar isi bukunya secara singkat. Kami akan memperlihatkan metode inti yang dimanfaatkan untuk penelitian di Indonesia (Surakarta/Solo) — dan Tanzania — dan hasil penelitiannya.

\section{Discourse Analysis in Interreligious Studies ${ }^{5}$}

Dari perspektif CDA pengetahuan ilmiah tidak hanya mendeskripsikan realitas, tetapi juga sebagian besar membentuk realitas yang mau dideskripsikan itu. Dasar teoretis untuk menemukan akan hal itu adalah sociocognitive discourse analysis (analisa wacana sosial kognitif). ${ }^{6}$ Menurut Flood agama terutama adalah kejadian komunikatif, percakapan. Oleh karena itu, dia sangat mendukung penggunaan metode penalaran. Dalam tahun-tahun terakhir teori naratif dan metode dialogis untuk meneliti agama menjadi makin penting. Pendekatan sosial kognitif dicirikan oleh unsur-unsur berikut: pengetahuan adalah cara untuk mengategorikan dunia sebagai hasil wacana; mengategorikan dunia sesuai kebudayaan dan hanya berlaku dalam konteks pada waktu itu yang kemudian bisa berubah lagi; pengetahuan diciptakan melalui suatu proses sosial melalui konstruksi keyakinan-keyakinan bersama dan bergumul mengenai definisi apa yang benar dan apa yang salah; beberapa bentuk aksi adalah alamiah dan dianggap biasa, maka konstruksi sosial pengetahuan memiliki konsekuensi sosial.

Norman Fairclough menawarkan suatu model dengan tiga dimensi: (1) wacana adalah suatu praktik yang sama dengan praktik yang lain, hal itu hanya dibedakan sebagai bentuk 
linguistik; (2) terjadi hubungan dialektis antara wacana (penalaran) dan kenyataan (nonpenalaran); (3) hubungan antara wacana dan realitas berjalan melalui praktik penalaran. Maka praktik itu menjadi sangat penting untuk menghubungkan bahasa dan realitas, teks dan konteks. Dalam penelitian ini, model inilah yang diikuti. Metode-metode yang dipakai adalah sebagai berikut. Yang pertama adalah deskripsi atau analisis dari ciri linguistik teks/wacana. Dalam tahap kedua praktik linguistik dikorelasikan dengan praktik sosial melalui praktik-praktik penalaran dan kemudian dalam tahap ketiga terjadi keterangan, ialah analisis dari efek-efek sosial kognitif dari teks di tiga tataran: pengetahuan atau keyakinan (pengartian); identitas-identitas sosial atau posisi-posisi subjek; dan hubungan-hubungan sosial.

Penerapan metode ini bagi penelitian interreligius adalah sebagai berikut: pertama, melihat bagaimana terjadi suatu proses untuk menentukan bagaimana agama dikonstruksikan; kedua, mengetahui bahwa ada persoalan kontroversial, karena beberapa metode dan perspektif tidak hanya tumpang tindih, tetapi sering kali juga campur aduk. Yang paling penting adalah bahwa hubungan antara wacana, percakapan, dan realitas adalah hubungan dialektis, bahwa ada kemungkinan untuk menjelaskan hubungan antara teks dan konteks. Ada orang yang menolak dan berkata bahwa tidak ada hubungan langsung antara teks dan konteks. Memang tidak ada hubungan langsung antara teks dan konteks, tetapi melalui proses penalaran bisa menemukan bahwa terjadi interaksi antara teks dan konteks. Ketiga, ada usaha untuk melalui penelitian ilmiah mereproduksikan gambaran-gambaran dan realitas yang dapat diandalkan. Bagaimana peneliti bisa mencapai itu? Pertama ada hubungan antara peneliti dan orang yang diteliti, dalam penelitian diusahakan melalui FGD. Kemudian ada kerja sama dalam tim peneliti di bidang yang sama, yang dibuat oleh Wijsen dengan asisten-asisten peneliti di Tanzania dan Indonesia, mengadakan pertemuan-pertemuan dengan ahli-ahli di bidang yang sama yang terjadi di Dar Es Salaam (Tanzania) dan Yogyakarta. Tahap ketiga adalah tulisan-tulisan yang transparan dan eksperimental untuk melaporkan data-data penelitian, sehingga orang lain dapat mengkritik penyataan-penyataan yang dirumuskan. Dan dalam semua tahap penelitian adalah refleksi terus-menerus dari para peneliti. Keempat, bisa dilihat bagaimana metode ini bisa dimanfaatkan sebagai studi kognitif dari agama, terutama dalam penelitian ini hubungan interreligius (IslamKristen). Dalam hal ini bisa dibedakan antara orang percaya sebagai individu-individu, orang yang mengidentifikasi mereka dengan agama atau lembaga agama, dan konteks kemasyarakatan di dalam lembaga-lembaga keagamaan yang mengoperasikan. Demikian juga interaksi antara guru dan murid, hubungan antara pemimpin agama dan orang yang beragama dapat diteliti, dan juga dengan efek-efek sosial kognitif dari khotbah-khotbah atau ajaran-ajaran agama-agama. 
Dalam bagian berikutnya akan dipresentasikan CDA tentang hubungan-hubungan antara bahasa religius dan (ketidakadaan) kohesi sosial di Indonesia.

\section{Muslim-Christian Relations in Indonesia ${ }^{7}$}

Dasar untuk deskripsi ini adalah transkripsi dari 24 FGD dilaksanakan di Solo antara 2008 dan 2010. "Peserta diseleksi berdasarkan kriteria berikutnya: kelamin, agama, umur, dan tingkat pendidikan. Ada empat kelompok laki-laki dan empat kelompok perempuan, terdiri atas tua dan muda, orang dengan pendidikan dan tanpa pendidikan, kali tiga: Muslim, Kristiani, dan campuran. Rata-rata ada enam partisipan dalam setiap kelompok, beberapa partisipan mengikuti dua kelompok, maka seluruhnya ada 120 partisipan. Kami juga mewawancarai beberapa informan inti seperti pemimpin politik dan pemimpin agama. Maksud dasar kami adalah untuk menganalisis dua masalah inti: bagaimana orang Muslim dan Kristiani berbicara tentang satu sama lain dan bagaimana orang Muslim dan Kristiani berbicara satu sama lain” (hlm. 92). Hasil dari 24 FGD selanjutnya dianalisa sesuai teori Analisa Wacana Sosial Kognitif, dalam tiga tahap. Pertama-tama hasil dideskripsikan dari segi linguistik, kata-kata dan metafora yang digunakan dalam kelompok-kelompok Muslim, Kristiani, dan campuran. Kemudian dilihat dari segi penalaran, menganalisa bagaimana peserta-peserta memproduksi (menyampaikan), dan mengonsumsikan teks-teks secara kognitif dan sosial. Dalam tahap ketiga dibuat penjelasan berdasarkan pertanyaan: apa hasil-hasil sosial kognitif dari diskusi para peserta? Analisis ini akhirnya dirumuskan dalam suatu kesimpulan tentang hubungan Muslim-Kristen di Solo sebagai wakil konteks Indonesia, dan kemudian dihubungi dengan konteks Indonesia. Wijsen sudah datang lebih daripada 20 tahun ke Indonesia. Tetapi pertanyaannya adalah apakah penelitian di dua kota, Solo di Indonesia dan Dar Es Salaam di Tanzania (di mana Wijsen sudah membuat penelitian sejak 1984) boleh diperluas hingga meliputi seluruh Indonesia dan Tanzania?

Dalam tiga bab berikutnya, yaitu bab 7, 8, dan 9, Wijsen dengan memanfaatkan macammacam teori memperlihatkan tiga hal yang mengarahkannnya kepada kesimpulan di bab 10 . Dalam bab 7 dengan judul konteks, perbandingan, dan percakapan, ia menitikberatkan, bahwa dalam konteks-konteks tertentu jika teks-teks dan kata-kata diperbandingkan satu sama lain selalu ada kesulitan. Walaupun di antara dua negara bisa diperlihatkan beberapa kebersamaan, dan bahkan ada gerakan-gerakan transnasional, sehingga nampaknya bahwa ada sedikit kesetaraan konseptual, akhirnya muncul bahwa misalnya jika memakai konsep God, terjadi macam-macam interpretasi, jika dilihat dari konteks Indonesia ada terjemahan Allah, tetapi juga ada Ketuhanan yang Maha Esa, yang oleh orang Indonesia diterjemahkan dalam bahasa Inggris, sangat 
berbeda. Ditemukan sembilan terjemahan resmi. Di Malaysia menurutnya awal mula orang Kristen sudah menggunakan nama Allah sebelum orang Islam, kemudian orang Islam melarang orang Kristen untuk memakai kata Allah. Maka Wijsen berbicara tentang suatu percobaan untuk menerjemahkan yang tidak dapat diterjemahkan. Maka daripada membandingkan harus melihat percakapan, karena komunikasi berarti mengkonstruksikan arti. Pesan tidak tetap, tetapi dikonstruksikan oleh interaksi antara pengirim dan penerima. Maka dalam komunikasi adalah mitra dalam proses mengkonstruksikan arti. "Hal itu memiliki konsekuensi yang sangat besar bagi studi hubungan antaragama. Menurut Pannikkar 'kita tidak bisa mengerti keyakinan utama seseorang, kecuali kita entah bagaimana membaginya"' (hlm. 123). Maka Wijsen mengakhiri bab ini dengan kesimpulan: "jika orang yang meneliti agama menerima bahwa orang yang beriman selalu mengkonstruksikan gambar-gambar dan stereotip-stereotip satu sama lain, studi tentang hubungan interreligius bukan tentang konversi tetapi tentang mengkonstruksikan identitas dalam interaksi” (hlm. 125). Dalam bab 8 Wijsen lebih mendalami bagaimana identitas religius terus-menerus berubah melalui pengaruh timbal-balik antara lain dengan teori bahwa seorang manusia selalu berdialog dengan diri sendiri karena seorang manusia merupakan suatu polifonik diri, mempunyai identitas hibrida, juga dari segi religius, karena dipengaruhi terus-menerus oleh macam-macam pengaruh religius. Dalam bab 9 diteliti sejauh mana terjadi hubungan antara bahasa religius, konflik sosial, dan kohesi sosial. Dapat disimpulkan (hlm. 166) bahwa tidak ditemukan hubungan langsung antara agama dan konflik dan juga bahwa beberapa penganut dari satu agama bisa memiliki sikap yang berbeda terhadap orang-orang bergama lain. Kebanyakan peserta penelitian tidak mau bahwa terjadi konfrontasi, konflik, tetapi mereka juga tidak mau bekerja sama. Kebanyakan mereka acuh tak acuh terhadap yang lain. Setelah kerusuhan mereka suka untuk secepat mungkin kembali ke kehidupan biasa. Dalam bab 10, bab terakhir, Wijsen merumuskan suatu teori percakapan tentang hubungan antaragama. Dalam epilog dengan judul “Agama dalam Ruang Publik", dia memberi suatu ringkasan dari seluruh buku antara lain di bawah subjudul hubungan Islam-Kristen inti dari penelitian di dalam FGD di Tanzania dan Indonesia. Buku ini sangat menarik, karena di dalamnya macam-macam teori dihubungkan satu sama lain, sehingga hubungan antar agama dibahas dari macam-macam segi dan diperlihatkan kelemahan dan kekuatan dari teori-teori tertentu.

Sudah disebutkan bahwa bahasa Wijsen singkat, tajam, dan jelas tetapi kadang-kadang terlalu singkat. Satu contoh adalah sebagai berikut: "President Sukarno recognized Confucianism as a religion in 1965, President Suharto de-recognized it in 1979, and President Yudhoyono recognized Confucianism again" (hlm. 50). Apa yang terjadi sebenarnya jauh lebih rumit. 
Beberapa tahun sesudah G 30 S, persis pada tanggal 6 Desember 1967, ditetapkan "Instruksi dari Presiden Indonesia (Inpres) Nomor 14 Tahun 1967 tentang Agama, Kepercayaan, dan Adat Istiadat Cina" dengan intinya "bahwa pelaksanaannya harus dilakukan secara intern dalam hubungan keluarga atau perorangan... perayaan pesta agama dan adat istiadat Cina dilakukan secara tidak menyolok di depan umum, melainkan dilakukan dalam lingkup keluarga" (Sairin, 1996: 104105). Dengan kata lain Presiden Soeharto tidak mengizinkan bahwa perayaan, upacara, dan pesta agama Tionghoa dilakukan secara umum, hanya diperbolehkan dalam rumah keluarga atau tempat tertutup. Hal itu diperkuatkan dengan surat edaran Departemen Dalam Negeri Republik Indonesia tanggal 18 November 1979 di dalamnya ditulis: "Agama yang diakui oleh Pemerintah ialah Islam, Katolik, Kristen/Protestan, Hindu, dan Buddha” (Sairin, 1996: 128). Maka Agama Kong $\mathrm{Hu} \mathrm{Cu}$ tidak disebut lagi. "Pada tanggal 17 Januari 2000, Presiden Abdurrahman Wahid mengeluarkan Keppres Nomor 6 tahun 2000 tentang pencabutan Inpres Nomor 14 tahun 1967 (...). Secara itu masyarakat Tionghoa diberikan kebebasan untuk menganut agama, kepercayaan, dan adat istiadatnya, termasuk merayakan upacara-upacara agama, seperti: Imlek, Cap Go Meh, dan sebagainya secara terbuka. Pada Imlek 2551 Kongzili di tahun 2000 Masehi, Majelis Tinggi Agama Konghucu Indonesia (MATAKIN) mengambil inisiatif untuk merayakan Imlek secara terbuka sebagai puncak Ritual Agama Khonghucu secara Nasional dengan mengundang Presiden Abdurrahman Wahid untuk datang menghadirinya. Pada tanggal 19 Januari 2001, Menteri Agama RI mengeluarkan Keputusan Nomor 13 tahun 2001 tentang penetapan Hari Raya Imlek sebagai Hari Libur Nasional Fakultatif. Pada saat menghadiri perayaan Imlek 2553 Kongzili, yang diselenggarakan Matakin di bulan Februari 2002 Masehi, Presiden Megawati Soekarnoputri mengumumkan mulai 2003, Imlek menjadi Hari Libur Nasional. Pengumuman ini ditindaklanjuti dengan dikeluarnya Keputusan Presiden Republik Indonesia Nomor 19 tahun 2002 tentang Hari Tahun Baru Imlek tertanggal 9 April” (Tim ASTRO, 2016). Demikian agama Kong $\mathrm{Hu} \mathrm{Cu}$ sebenarnya sudah diakui dan dihargai lagi sebagai agama di Indonesia. Maka prosesnya jauh lebih rumit daripada yang ditulis terlalu singkat oleh Wijsen dalam satu kalimat.

\section{BUKU CHRISTIANITY AND OTHER CULTURES}

Dalam buku ini Wijsen membahas perkembangan metode-metode dan teori-teori ilmiah yang ia gunakan selama lebih dari 30 tahun sebagai seorang peneliti. Untuk itu dia mengumpulkan 8 artikel yang ia tulis antara tahun 1997 dan 2014, hanya ia perlu memperbaiki bahasa sedikit di 
sini-sana, untuk memperlihatkan perkembangan hal itu. Dalam Introduction (hlm. 15-29), dengan judul My "Pilgrimage" in Mission Studies ("perziarah" saya meneliti misi), dia melukiskan secara singkat dan jelas perubahan-perubahan yang terjadi dalam penggunaan metode-metode, terutama metode lingkaran pastoral. ${ }^{8}$ Maka dengan meringkaskan introduksi ini garis besar buku sudah menjadi jelas. Awal mula ada cerita tentang seorang misionaris Barat yang bertemu seorang tua adat suku Sukuma di Tanzania yang menyelaskan bahwa orang Barat mempunyai agama Kristiani tertentu, tetapi orang Sukuma juga mempunyai kepercayaan sendiri, antara lain kepercayaan pada nenek moyang mereka dan menurut tetua adat itu semua orang mempunyai agama sendiri, tetapi juga semua agama baik-baik saja. Dari awal mula karier akademis prinsip utama bagi Wijsen adalah mengerti proses-proses akulturasi yang dialami oleh orang pada waktu mereka bertemu kebudayaan-kebudayaan yang lain. Agama Kristiani sendiri juga merupakan (produk) kebudayaan, maka oleh karena itu judul buku ini sengaja dirumuskan sebagai Agama Kristiani dan budaya-budaya lain.

Misi didefinisikan sebagai komunikasi cross-cultural Kristiani atau komunikasi dari iman Kristiani. Hal itu baik antara gereja-geraja dengan konteks berbeda atau latar belakang berbeda, perspektif ekumenis, maupun dengan agama-agama lain. Maka misi dan misiologi tidak bisa diganti dengan teologi interkultural (yang dibahas lebih luas dalam bab 1 dengan judul: "Teologi Interkultural sebagai Ganti Misiologi?") atau komparasi teologi.

Dalam hubungan dengan suku Sukuma dia menemukan empat sikap orang Sukuma terhadap hubungan kebudayaan, yang memengaruhi sampai sekarang penelitian Wijsen. Empat sikap adalah sebagai berikutnya. Pertama, beberapa orang hidup dalam dua sistem, misalnya Hari Minggu mereka adalah orang Kristiani, hari-hari yang lain mereka adalah penganut agama asli. Kedua, orang-orang lain menolak seluruhnya satu dari dua sistem, mereka menjadi Kristiani secara Eropa atau seluruhnya percaya pada nenek-moyang. Ketiga, orang-orang lain lagi, terutama orang intelektual, menolak dua-duanya, mereka menjadi sosialis atau humanis dengan pandangan dunia sekuler. Keempat, sejumlah cukup besar orang menciptakan perpaduan antara agama Afrika dan pesan Kristiani.

Dalam misiologi adalah empat perspektif, yaitu: historis, empiris, normatif, dan strategis, dengan empat subdisiplin ilmu, yaitu: antropologi, sejarah, teologi, dan pedagogi misi. Dan menurut Wijsen misiologi merupakan bagian dari teologi praktis. Oleh karena itu, penelitian misiologis sering kali dibuat dengan metode lingkaran pastoral yang kemudian berkembang dalam penelitiannya menjadi spiral praktis teologis (dibahas dalam bab 2 dengan judul "Spiral Teologis-Praktis Ditinjau Ulang") dengan empat tahap. Tahap pertama adalah memperoleh 
pengetahuan tentang suatu praktik yang dianggap problematis, disebut sebagai observasi (partisipatif). Tahap ini dijelaskan dalam bab 3 dengan judul "Dialog dan Sinkretisme dalam Kekristenan di Afrika”. Dalam tahap kedua peneliti mendapat wawasan tentang praktik tersebut, disebut interpretasi. Tahap ini dijelaskan dalam bab 4 dengan judul "Kebangkitan Agama di Dunia Trans-modern". Dalam tahap ketiga praktik itu dievaluasi. Tahap ini dijelaskan dalam bab 5 dengan judul "Kekristenan di Afrika: Sinkretisme atau Inkulturasi?” Dalam tahap terakhir diperlihatkan syarat-syarat yang memungkinkan suatu pembaharuan dari keadaan sebelumnya, disebut inovasi dan dibahas dalam bab 6 dengan judul "Misi: Dari Inkulturasi ke Interkulturasi”.

Yang diharapkan adalah bahwa innovasi akan dipraktikkan dan kemudian proses lingkaran bisa dimulai lagi dengan penilaian praktik, menemukan lagi masalah dalam harapan keadaan akan menjadi lebih baik, oleh karena itu kata lingkaran diganti dengan kata spiral, karena proses akan jalan terus-menerus, dengan harapan bahwa setiap kali keadaan akan menjadi lebih baik.

Sudah disebut bahwa komunikasi crosscultural merupakan inti misiologi bagi Wijsen, Ia membuat suatu kesimpulan dalam buku dengan judul "Komunikasi Antara Orang Eropa dengan Orang Afrika". Tetapi dengan itu buku belum diselesaikan, karena sebagai tambahan masih ada satu Epilog dengan judul "Dari Analisis Sosial ke Analisis Penalaran" di mana dia membahas perubahan metode penelitian pribadi yang sudah dibahas di atas. Hal itu terjadi karena baginya komunikasi, termasuk bahasa, dari awal mula kariernya selalu merupakan inti penelitian. Sekarang ditambah dengan metode Dialogical Self Teori. Ia menulis, "Melihat saya sendiri dari perspektif ini, saya melihat saya sendiri sebagai suatu polifonic self; sebagian orang Belanda, walaupun khas seorang Selatan; sebagian orang Tanzania, walaupun lebih seorang Sukuma daripada seorang Chagga; dan sebagian orang Indonesia, walaupun lebih seorang Jawa daripada seorang Batak, untuk menggeneralisasi. Saya sudah sering kali ditanya apakah saya melihat suatu kontradiksi atau bahkan suatu konflik dalam mengatur posisi saya sendiri sebagai seorang misiolog atau seorang ahli studi agama-agama. Saya selalu menjawab 'tidak'. Saya sekarang mengerti bahwa saya diri sebagai misiolog dan ahli studi agama-agama adalah 'posisi-posisi saya' dalam 'lapis-lapis identitas' saya” (hlm. 26).

Metode-metode untuk membuat penelitian misiologis terutama crosscultural yang dijelaskan oleh Wijsen dalam buku Christianity merupakan secara keseluruhan perkembangannya sebagai seorang ilmuan dengan mempertanggungjawabkan metode-metode yang hendak dimanfaatkan. Hal itu bisa menjadi suatu sumber yang kaya bagi orang yang juga hendak membuat penelitian. Dua buku yang dibahas ini memberi suatu sumbangan yang sangat berharga tentang metode-metode yang bisa dimanfaatkan untuk membuat penelitian. 
Tetapi saya merasa sebagai seorang misiolog, bahwa metode-metode-nya sangat spesifik, dihubungkan dengan teologi praktis dan dilihat dari segi kekristenan atau iman Kristiani.

Bagi saya misi dan misiologi juga selalu harus dilihat sebagai salah satu tugas gereja, bagi saya misiologi adalah bagian dari eklesiologi. Dalam konteks Asia hal itu berarti sesuai konsep misi FABC bahwa gereja harus berdialog dengan konteks kemiskinan, kebudayaan, dan pluralitas agama. Maka bagi saya unsur dari lingkaran pastoral yang penting juga memperhatikan, dalam tahap pertama dan kedua, konteks dari segi sosial-politik-ekonomi untuk menemukan dasar dari kemiskinan dan ketidakadilan dalam harapan berdasarkan refleksi teologis agar dapat membuat usulan untuk memperbaiki keadaan. Menurut saya, untuk dialog dengan kebudayaan, teologi interkultural tetaplah sangat penting bagi gereja untuk menemukan bagaimana gereja bisa berkembang dalam dan diperkayakan oleh dialog dengan kebudayaan lokal. Melalui metode CDA bisa ditemukan bagaimana hubungan antaragama berkembang. Itu satu hal menarik, tetapi menurut saya hal ini juga sangat tergantung pada pengalaman orang yang sangat subjektif dan dalam konteks Jawa mereka mungkin berbicara halus, karena tidak mau menyakiti satu sama lain. Saya merasa tugas gereja juga adalah untuk—-berdasarkan hasil penelitian semacam ini-mencari jalan, untuk membangun hubungan dengan orang beragama lain yang juga sungguh-sungguh percaya pada Tuhan dan mencari kehadiran Tuhan dalam kehidupan mereka yang lebih baik, dan oleh karena itu seharusnya diarahkan untuk hidup bersama serta bekerja sama dengan baik demi kesejahteraan bersama. Itu dapat dilakukan misalnya melalui teologi agama-agama dan dialog antaragama. Maka, menurut saya, tugas misiologi yang penting adalah merefleksikan bagaimana gereja bisa mewujudkan misinya berdasarkan dialog rangkap tiga dengan konteks Asia.

\section{Catatan}

1 Teori dari Joe Holland dan Peter Henriot SJ (1983). Oleh Frans Wijsen disesuaikan dengan penelitiannya di Tanzania.

2 Dia menggantikan profesor Rogier van Rossum ss.cc., dosen misiologi yang memberikan semangat untuk studi misiologi pada Frans Wijsen (dan juga pada penulis resensi ini) di HTP, Heerlen.

3 Buku itu menjadi bahan untuk kuliah S-2 teologi interkultural di UKDW bersama penulis (lih. de Jong, 2008: 117-131) dan ia juga memberi makalah dalam seminar dengan topik The Next Christendom, 2 April 2008, di UKDW (Wijsen, 2008).

${ }^{4}$ Untuk meneliti identitas seseorang yang dari satu segi dipengaruhi oleh macam-macam pengalaman berbeda, juga dari orang liyan, tetapi dari segi yang lain seseorang sebagai manusia mempunyai juga banyak kebersamaan dengan orang liyan, maka untuk meneliti itu dia akan memanfaatkan The Critical Self Theory, dari Prof. H. Hermans c.s.

5 Judul dari Bab 4, hlm. 53-73. Kami meringkaskan bab ini untuk menjelaskan inti dari sociocognitive discours analyisis. 
6 Dua sumber penting untuk teori ini adalah Gavin Flood (1999) dan terutama Norman Fairclough (2007).

7 Judul dari Bab 6, hlm. 91-106. Kami menjelaskan terutama bagaimana metode CDA dipergunakan secara praktis di Solo untuk mengumpulkan data-data (hlm. 91-92) dan kemudian secara singkat cara hasil itu dianalisis dengan sociocognitive $C D A$.

${ }^{8}$ Untuk mendeskripsikan perkembangannya dia mengutip lumayan banyak karya ilmiah yang ditulisnya, terutama buku dan artikel, yang ditulis antara 1981 sampai dengan 2014.

\section{DAFTAR PUSTAKA}

De Jong, Kees. 2008. “Keanekaragaman Bentuk Kekristenan Global”. Gema Teologi. Vol. 32, No. 1, April.

Fairclough, Norman. 2007. Discourse and Social Change. Reprint ke-9, asli 1992. Cambridge U.K/Malden USA: Polity Press.

Flood, Gavin. 1999. Beyond Phenomenology: Rethinking the Study of Religion. London dan New York: Cassell.

Holland, Joe dan Peter Henriot, SJ. 1983. Social Analysis, Linking Faith and Justice. Maryknoll, New York: Orbis Books.

Jenkins, Philip. 2007. The Next Christendom: The Coming of Global Christianity. Reviseds and expanded edition. Oxford: Oxford University Press.

Sairin, Weinata. 1996. Himpunan Peraturan di Bidang Keagamaan. Jakarta: BPK Gunung Mulia.

Tim ASTRO. 2016. "Sejarah Tahun Baru Imlek di Indonesia”. https://cvastro.com/sejarah-tahunbaru-imlek-di-indonesia.htm. Diakses 15 Agustus 2016.

Wijsen, F.J.S. 1993. There is Only One God: A Social-Scientific and Theological Study of Popular Religion and Evangelization in Sukumaland, Nortwest Tanzania. KTC Series No. 22. Kampen: Kok (Diterjemahkan dalam bahasa Indonesia oleh Steve Gaspers. 2010. Buahbuah Roh: Menjalankan Riset Sosial Partisipatif di Belahan Dunia Selatan. Yogyakarta: Divisi Penerjemahan. Yogyakarta: Penerbitan dan Toko Buku Fakultas Teologi Duta Wacana/Duta Wacana University Press).

Wijsen, Frans. 2008. “Kekristenan Global: Sebuah Perspektif Eropa”. Gema Teologi. Vol. 32, No. 1, April. 
. 2012. "The Practical-Theological Spiral Revisited from Social to Discursive Analysis". Dalam Robert Setio dkk. (eds.). Teks dan Konteks yang Tiada Bertepi. Semarang: Penerbit Pustaka Muria.

. 2014. "What is Intercultural about Intercultural Theology?". Gema Teologi. Vol. 38.

, Peter Henriot dan Rodrigo Mejia (eds.). 2005. The Pastoral Ciricle Revisited: A Critical Quest for Thruth and Transformation.

dan Robert Schreiter (eds.). 2007. Global Christianity: Contested Claims. Amsterdam/ New York: Rodopi. 